\title{
Relato de experiência de um protocolo de implementação de cantinas escolares saudáveis
}

\section{Experience report of a protocol for the implementation of healthy school canteens}

\author{
Naiane Gomes Braz' \\ Greisse Viero da Silva Leal" iD \\ Carla Cristina Bauermann \\ Brasil" (iD) \\ Cariza Teixeira Bohrer" (iD \\ Daniela Paini"I ID \\ Vanessa Ramos Kirsten",** (iD
}

\begin{abstract}
RESUMO
Introdução: Devido aos altos índices de sobrepeso e obesidade entre crianças e adolescentes e à baixa qualidade nutricional de alimentos comercializados em escolas, uma das estratégias utilizadas para promoção da alimentação saudável é a implementação da cantina escolar saudável. Objetivo: Relatar a experiência da implementação de cantinas escolares saudáveis. Método: São apresentadas nove etapas para o processo de implementação em escolas. Além das etapas, são descritos instrumentos utilizados. Resultados: Participaram duas escolas. Foram realizadas reuniões com o grupo de integrantes do projeto, diretores e proprietários das cantinas, realização de pesquisa de satisfação com os alunos, entrevista com o proprietário da cantina, análise dos alimentos comercializados, aplicação de lista de verificação das condições higiênico-sanitárias dos estabelecimentos e realização de educação alimentar e nutricional com os alunos e proprietário da cantina. Conclusões: As atividades propostas podem auxiliar na realização de diagnósticos e estratégias de mudanças do comércio de alimentos nas cantinas, o que leva à conclusão de que elas foram importantes. Além disso, esse estudo servirá de apoio para profissionais de saúde e educação, bem como para a comunidade escolar, que visem regulamentar as cantinas escolares de seus municípios em ambientes mais saudáveis.
\end{abstract}

PALAVRAS-CHAVE: Alimentação Saudável; Alimentação Escolar; Leis sobre Alimentos; Consumo Alimentar

\begin{abstract}
Introduction: Due to the high rates of overweight and obesity among children and adolescents and the low nutritional quality of food sold in schools, one of the strategies used to promote healthy eating is the implementation of the Healthy School Canteen. Objective: To report the experience of implementing Healthy School Canteens. Method: Nine steps are presented for the implementation process in schools. Results: 2 schools participated. Meetings were held with the group of members of the project, directors and owners of the canteens, conducting a satisfaction survey with students, interviewing the owner of the canteen, analyzing the food sold, applying a checklist of the hygienic conditions of the establishments and carrying out food and nutrition education with the students and the owner of the canteen. In addition to the steps, instruments used are described. Conclusions: The proposed activities can assist in carrying out diagnoses and strategies for changing the food trade in canteens, concluding that these were important. In addition, this study will provide support for health and education professionals, as well as for the school community, which aim to regulate school canteens in their municipalities as healthier environments.
\end{abstract}

KEYWORDS: Healthy Eating; School Feeding; Food Laws; Food Consumption 


\section{INTRODUÇ̃̃O}

Globalmente os índices de sobrepeso e obesidade aumentaram cerca de $27,5 \%$ para adultos e $47,1 \%$ para crianças entre 1980 e 2013. Nos países desenvolvidos, a prevalência de sobrepeso e obesidade entre crianças e adolescentes de 2 a 19 anos aumentou de $16,9 \%$ para $23,8 \%$ nos meninos e de $16,2 \%$ para $22,6 \%$ nas meninas entre os anos de 1980 e 2013. Nos países em desenvolvimento, os índices aumentaram de $8,1 \%$ para $12,9 \%$ em meninos e de $8,4 \%$ para $13,4 \%$ em meninas entre 1980 e $2013^{1}$. Dados da Pesquisa Nacional de Saúde do Escolar (PeNSE) demonstram que o estado nutricional dos adolescentes escolares do Brasil se caracteriza pela baixa prevalência de déficit de peso e pela prevalência elevada do excesso de peso. E em relação ao espaço social escolar, as unidades particulares apresentam risco de excesso de peso mais elevado².

Assim, políticas públicas, programas e conjuntos estratégicos têm sido lançados com intuito de prevenção e controle do excesso de peso e obesidade, não só de crianças e adolescentes, mas da população em geral. Dentre as quais se destacam: a Política Nacional de Alimentação e Nutrição (PNAN) ${ }^{3}$, que baseia suas ações em sete diretrizes, com destaque para a $2^{\text {a }}$ diretriz - Promoção da Alimentação Adequada e Saudável; o Programa Nacional de Alimentação Escolar (PNAE)4; o Programa Saúde na Escola (PSE) ${ }^{5}$, que tem por finalidade ampliar as questões relativas as ações de saúde aos alunos da rede pública de ensino; Dez Passos para a Promoção da Alimentação Saudável nas Escolas ${ }^{6}$, que têm por objetivo promover a saúde e favorecer a adesão dos escolares a hábitos alimentares saudáveis e adequados; a Resolução $\mathrm{n}^{\circ}$ 24, de 29 de junho de 2010, da Agência Nacional de Vigilância Sanitária (Anvisa), que trata da publicidade dos alimentos com intuito de impedir o aumento das doenças crônicas não transmissíveis ${ }^{7}$; a Portaria Interministerial $n^{0} 1.010$, de 8 de maio de 2006, que especifica diretrizes para a Promoção da Alimentação Saudável nas Escolas ${ }^{8}$, dentre outras.

Uma das estratégias utilizadas que visam a promoção da alimentação saudável para a comunidade escolar é a implementação da Cantina Saudável ${ }^{9}$. As cantinas são uma das fontes de acesso a alimentos nas escolas e está inserida com intuito de comercializar gêneros alimentícios na comunidade escolar ${ }^{10}$. Entende-se por cantina escolar saudável aquela que oferta alimentos de boa qualidade nutricional, em condições higiênico-sanitárias adequadas, para garantia da segurança alimentar e nutricional da comunidade escolar, bem como do respeito pela cultura e pelos hábitos alimentares de cada um .

No entanto, alguns estudos têm demonstrado que nas cantinas escolares avaliadas são oferecidos alimentos com alto teor de gordura, açúcar e sódio ${ }^{11,12,13}$. Considerando que a formação dos hábitos alimentares e estilos de vida começa na infância e que a escola é um ambiente promotor de saúde, verifica-se a importância da implementação de cantinas escolares saudáveis. Esta ação auxilia na conscientização não só dos alunos, mas também dos professores e dos demais integrantes da formação escolar na busca por uma alimentação mais saudável e adequada e da promoção da saúde ${ }^{14}$.
No Brasil, em 2010 foi publicado pelo Ministério da Saúde um Manual de Cantinas Saudáveis ${ }^{15}$ direcionado às cantinas de escolas particulares. Além disso, existem poucos estudos que abordem metodologias de implementação da Cantina Saudável no país ${ }^{16,17,18}$, por isso a necessidade de que se desenvolvam alternativas ampliadas, visto a imensa diferença existente entre as escolas brasileiras, que auxiliem tanto as instituições públicas quanto as privadas no processo de implementação de ambientes escolares promotores de alimentação saudável.

Portanto, o objetivo do presente estudo foi relatar a experiência da implementação de cantinas escolares saudáveis.

\section{MÉTODO}

Trata-se de um relato de uma experiência sobre a implementação de propostas educativas para a promoção de cantinas escolares saudáveis realizada de maio a dezembro de 2017 em duas escolas de um município do interior do Rio Grande do Sul, participantes de um projeto de extensão vinculado ao Curso de Nutrição da Universidade Federal de Santa Maria, com duração de 2 meses.

Participaram dessa experiência as escolas que possuíam cantina escolar e que aceitaram participar da implementação. As partes envolvidas foram: os proprietários das cantinas escolares, os(as) diretores(as) das escolas, os alunos de ensino médio, os professores e os integrantes do projeto. As escolas foram convidadas a participarem da atividade por meio de reuniões realizadas com a direção e o proprietário da cantina.

Para dar início às atividades de implementação da Cantina Saudável nas escolas, foi realizada uma reunião com os(as) diretores(as) e proprietários(as) do estabelecimento para apresentação do projeto, dos seus objetivos e das etapas previstas. A reunião foi realizada nas respectivas escolas e não foram muito longas para garantir que os participantes permanecessem focados nas propostas apresentadas. Para a sensibilização dos participantes, foram utilizados argumentos convincentes, enfatizando, por exemplo: o quanto a escola é importante para a formação de bons hábitos alimentares e que a cantina tem um papel fundamental nesse processo; além disso foram mencionadas as legislações que existem sobre a regulamentação destes espaços e dos altos índices de sobrepeso e obesidade entre crianças e adolescentes no Brasil. Ainda, caso a escola possuísse os dados do estado nutricional dos alunos, estes poderiam ser utilizados na estratégia apresentada. Além disso, como se espera em qualquer atividade extensionista, foram expostas as melhorias que o projeto proporcionará à escola e à cantina, tanto nas condições higiênico-sanitárias como na oferta dos alimentos mais saudáveis à comunidade escolar.

O projeto só foi realizado nas escolas em que houve consentimento de ambas as partes. Após o aceite, o grupo foi organizado por escola formado por alunos de graduação e professores, que eram responsáveis pela definição, organização e realização das atividades: 
a. As reuniões de planejamento do projeto aconteciam semanalmente;

b. Organização, planejamento e definição da coleta de dados: o desenvolvimento de instrumentos e coleta de dados para avaliar os alimentos comercializados, as condições higiênicas e as motivações dos clientes para a compra dos alimentos no estabelecimento.

Para avaliar a satisfação da cantina pelos alunos, foram elaborados questionários com as seguintes perguntas: motivos que levam os alunos a comprarem na cantina, frequência com que compram, opinião sobre o preço dos alimentos, satisfação sobre os alimentos comercializados, conhecimento sobre alimentação saudável, existência de meios que induzam os alunos a comprarem os alimentos, como promoções e higiene do estabelecimento. 0 Quadro 1 demonstra a etapa do diagnóstico de satisfação dos clientes em relação à cantina.

Para analisar as condições higiênico-sanitárias das cantinas foi utilizada a lista de verificação para categorização dos serviços de

Quadro 1. Pesquisa de satisfação aplicada aos alunos das escolas.

PESQUISA DE SATISFAÇÃO - CANTINA DA ESCOLA

Nome da Escola:

1. Qual é a sua idade:_anos Em que ano você está?

2. Você costuma tomar café da manhã? ( ) Sim ( ) Não

Se não, por quê?

3. Você costuma trazer lanche de casa? ( ) Sim ( ) Não

Se não, por quê?

4. Você consome a merenda oferecida pela escola? ( ) Sim ( ) Não

Se não, por quê?

5. Você compra alimentos na cantina da escola? ( ) Sim ( ) Não

6. Se sim, qual é a frequência? ( ) Todos os dias ( ) 1 x na semana ( ) 3 x na semana ( ) esporadicamente ( 2 x no mês) ( ) Quase nunca (menos de 1 x no mês)

7. Em média, quanto você gasta por dia na cantina de sua escola (em reais)? R\$

8. Qual sua opinião quanto ao preço dos alimentos ofertados na cantina?

( ) Acessível ( ) Muito caro

9. Se considerar muito caro, qual é o alimento e o preço que você acha muito caro?

10. Sobre os alimentos da cantina:

a. Quais você costuma comprar com mais frequência?

b. Você costuma comprar estes alimentos por algum motivo especial?

c. Você está satisfeito com os alimentos oferecidos na cantina? ( ) Sim ( ) Não

d. Se não, marque com um X, o motivo:

() Variedade () Qualidade () Valor ( ) Aparência () Sabor

11. Quais motivos o levam a comprar na cantina? ( ) Merenda não te satisfaz ( ) Preferência ( ) Influências (amigos/mídia) ( ) Preço ( ) Sabor ( ) Outros/Qual(is)?

12. É oferecido maionese, catchup e/ou mostarda quando você compra um lanche? ( ) Sim ( ) Não

13. Tem algum alimento que não tem e você gostaria que tivesse na cantina?

( ) Sim ( ) Não Se sim, qual(is)?

14. Você costuma comprar mais de um alimento na cantina no mesmo dia?

( ) Sim ( ) Não Caso a resposta seja sim, quais alimentos?

15. Há promoções na cantina da escola que te levam a comprar mais?

( ) Sim ( ) Não Quais?

16. A cantina oferece opções de lanches saudáveis? ( ) Sim ( ) Não Se sim, quais?

18. 0 que você acha de ter uma cantina saudável na sua escola?

( ) Legal ( ) Não gostaria ( ) Tanto faz

19. Em algum momento, você recebeu alguma informação sobre a alimentação saudável?

( ) Sim ( ) Não

Se a resposta for sim, qual informação recebeu?

20. Dentre os alimentos disponíveis na cantina, existem alimentos que você considera saudável?

( ) $\operatorname{Sim}$ ( ) Não

Quais e por quê?

21. Se houvesse uma oferta maior de lanches saudáveis na cantina, você compraria?

( ) Sim ( ) Não Por quê?

22. Se você puder ajudar nesta cantina saudável, quais seriam suas sugestões?

23. Você considera o local da cantina limpo? ( ) Sim ( ) Não

24. Você está satisfeito com a higiene do atendente que faz a entrega dos alimentos oferecidos na cantina?

( ) Sim ( ) Não Se a resposta for NÃO o que pode ser mudado?

25. De que forma os alimentos são oferecidos? ( ) Guardanapos ( ) Saquinhos Descartáveis ( ) Copo plástico com tampa ( ) Copo plástico sem tampa ( ) Outro:

26. Na cantina tem geladeira e estufa (quente) para armazenar alimentos quentes/frios? ( ) Sim ( ) Não

27. Quem prepara os alimentos usa touca, luva e avental? ( ) Sim ( ) Não

28. A pessoa responsável pelo caixa (dinheiro) é a mesma que entrega os alimentos/ bebidas?

( ) Sim ( ) Não

29. Já encontrou fio de cabelo, insetos e/ou algum objeto estranho ao comprar um alimento/bebida? ( ) Sim ( ) Não Se sim, o que encontrou?

30. Já comprou algum alimento/bebida na cantina com cheiro, aparência ou sabor estranho? ( ) Sim ( ) Não Qual(is)?

31. É disponibilizado na cantina/escola sabonete líquido, papel toalha e álcool para lavar as mãos? ( ) Sim ( ) Não

Se sim, você lava as mãos antes de se alimentar? ( ) Sim ( ) Não

32. Já observou a presença de algum animal/praga no ambiente e/ou arredores da cantina? ( ) Sim ( ) Não

Se sim, quais? ( ) Baratas ( ) Ratos ( ) Formigas ( ) Aranhas ( ) Cães/gatos. Outros:

33. Observou alguma vez se quem prepara o alimento lava as mãos em algum momento?

( ) $\operatorname{Sim}$ ( ) Não

34. Você considera os funcionários: ( ) Educados ( ) Acolhedores ( ) Prestativos ( ) Irritados ( ) Indispostos ( ) Mal-humorados ( ) Outro OBRIGADA PELA PARTICIPAÇÃO! COMENTÁRIOS.

Fonte: Elaborado pelos autores, 2019. 
alimentação ${ }^{19,20}$. A lista contém 51 questões que refletem maior impacto à saúde e é subdividida em nove categorias, sendo elas: Abastecimento de água (categoria A); Estrutura (categoria B); Higienização de instalações, equipamentos, móveis e utensílios (categoria C); Controle integrado de vetores e pragas urbanas (categoria D); Manipuladores (categoria E); Matéria-prima, ingredientes e embalagens (categoria F); Preparação do alimento (categoria G); Armazenamento, transporte e exposição do alimento preparado (categoria $\mathrm{H}$ ) e Responsabilidade, documentação e registro (categoria I). 0 descumprimento dos três primeiros itens da lista de verificação, referentes à categoria Abastecimento de água (categoria A), é eliminatório, ou seja, exclui o estabelecimento da continuidade da aplicação da lista de verificação e consequentemente da sua categorização. A coleta de dados foi realizada in loco, agendada previamente, durante $o$ processo produtivo de alimentos. Os dados foram digitalizados no Sistema de Avaliação e Monitoramento de Risco Sanitário em Serviço de Alimentação (Siars)a. Este sistema gera relatórios específicos para avaliação das condições higiênico-sanitárias dos serviços de alimentação, sendo a pontuação apresentada em percentuais de adequação ${ }^{21}$.

Antes de avaliar os alimentos comercializados no estabelecimento, foi realizada uma entrevista com os proprietários das cantinas, por meio de gravação e transcrita na sequência (Quadro 2). Após a transcrição, foi efetuada a análise das respostas do proprietário do estabelecimento. A partir disso, também foram planejadas ações de educação alimentar e nutricional com toda a comunidade escolar e proprietários da cantina.

Em seguida, a análise dos alimentos comercializados nas cantinas foi realizada utilizando uma lista (Quadro 3) com diversos alimentos, que teve o intuito de fazer um diagnóstico dos alimentos comercializados e da existência de propagandas que estimulassem o consumo de alimentos não saudáveis, proposto no Manual das Cantinas Escolares Saudáveis ${ }^{15}$.
A análise dos dados foi realizada por meio de estatística descritiva simples e análise de discurso. Para cada cantina escolar foi discutido um plano de ação de acordo com os resultados encontrados. Os planos de ação foram divididos em atividades educativas sobre as condições higiênicas e de educação alimentar e nutricional (para a cantineira e para os alunos).

O planejamento e a implementação das ações nas escolas foram baseados em programas de Educação Alimentar e Nutricional. Foram elencados temas a serem melhorados nos locais (por meio dos questionários anteriormente descritos) e planejadas ações.

Este projeto foi financiado por meio de aprovação em edital de auxílio à extensão (FIEX) da Universidade Federal de Santa Maria no ano de 2017 e foi integrado com a disciplina de Educação Alimentar e Nutricional.

\section{RESULTADOS E DISCUSSÃO}

Apresentamos, na seção de resultados, as etapas desenvolvidas para a implementação da cantina escolar saudável, baseadas em ações já realizadas anteriormente no próprio município ${ }^{21}$, no Distrito Federal, em escolas estaduais de Santa Catarina e do município de Florianópolis ${ }^{12,17,18}$. Esse relato de experiência pode servir como um material de apoio a comunidade escolar, secretarias municipais e estaduais de educação, bem como profissionais da área da saúde que desejem adequar as cantinas escolares de seu município (Quadro 4).

Embora o tema seja de grande relevância para a saúde da comunidade escolar, alguns proprietários de cantinas escolares alegam que a "cantina saudável" é inviável economicamente ${ }^{14} e$, ainda, que têm medo de fiscalização. Provavelmente por esses motivos, apesar de o município possuir seis cantinas escolares, apenas duas (uma de âmbito público e a outra, privado) participaram do estudo. Cada escola continha uma cantina, com duas

Quadro 2. Questionário utilizado para entrevista com o proprietário da cantina.

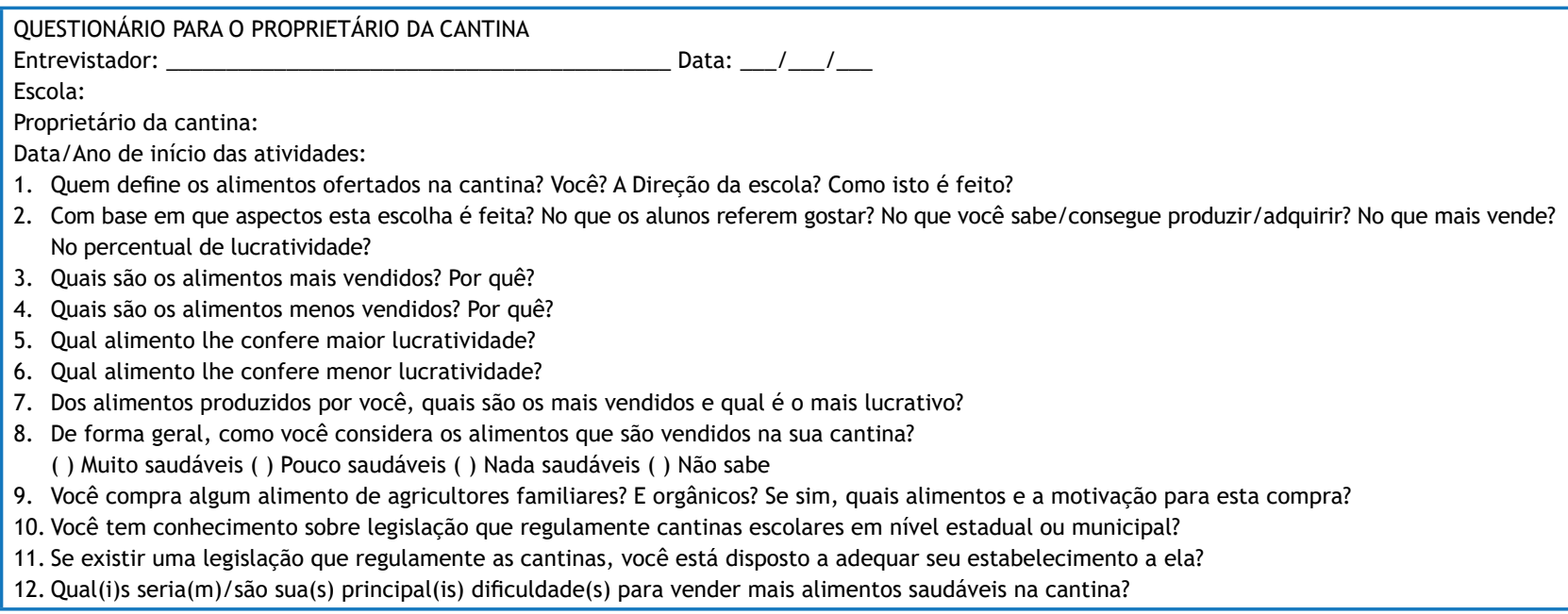

Fonte: Elaborado pelos autores, 2019.

\footnotetext{
a versão 1.013. Disponível: http://www.cecanebs.com.br/siars/index.html
} 
Quadro 3. Questionário para avaliação dos alimentos comercializados nas cantinas.

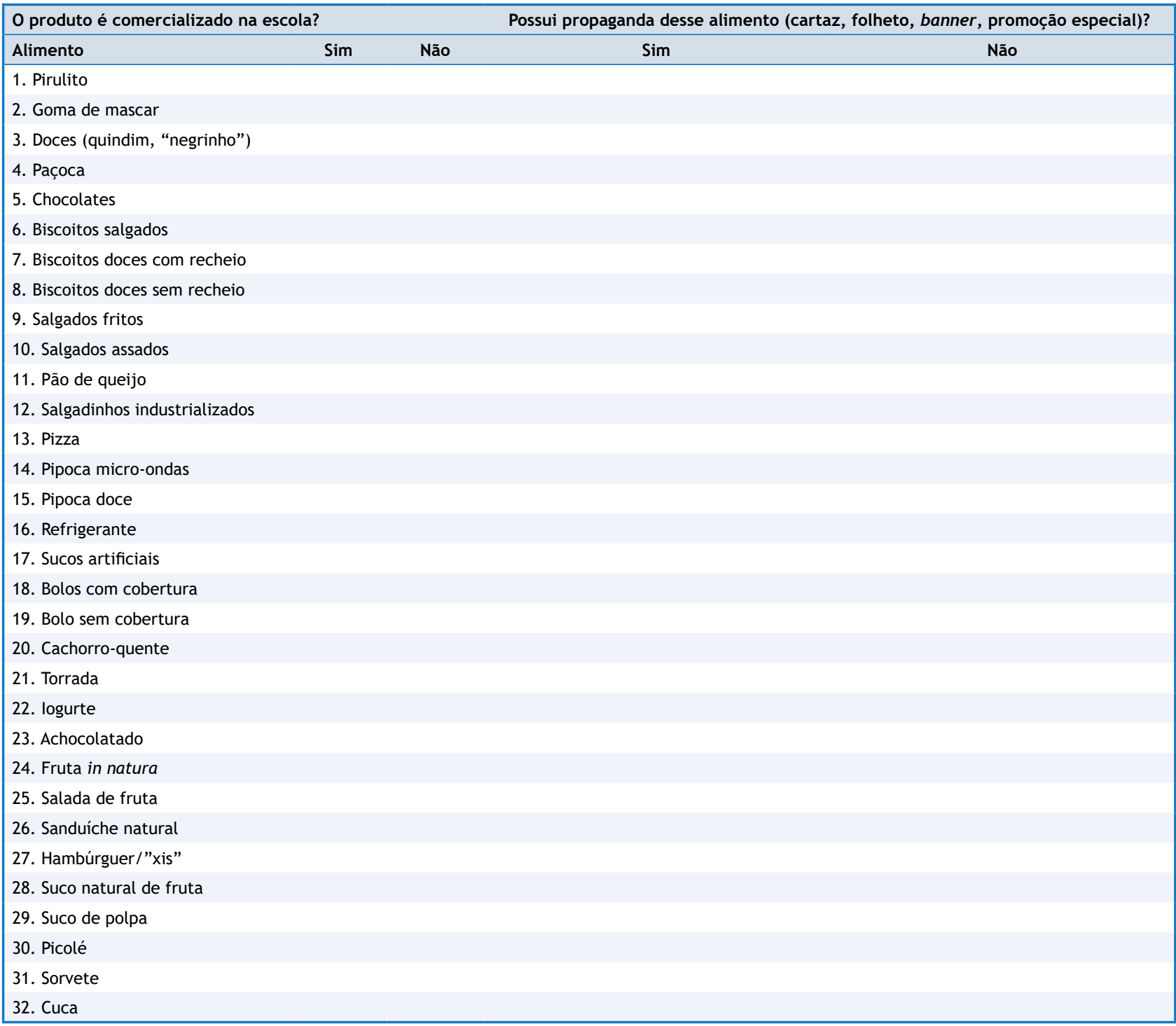

Fonte: Elaborado pelos autores, 2019.

Quadro 4. Descrição das atividades realizadas ao longo do estudo.

\begin{tabular}{|lr|}
\hline Etapa & O que foi realizado \\
\hline $1^{\text {a }}$ & Sensibilização \\
$2^{\text {a }}$ & Planejamento \\
$3^{\text {a }}$ & Diagnóstico de satisfação da cantina \\
$4^{\text {a }}$ & Análise dos resultados \\
$5^{\text {a }}$ & Justificativa para a mudança \\
$6^{\text {a }}$ & Plano de ação \\
$7^{\text {a }}$ & Diagnóstico das condico da oferta de alimentos higiênico-sanitárias \\
$8^{\text {a }}$ & Implementação das ações \\
$9^{a}$ &
\end{tabular}

Fonte: Elaborado pelos autores, 2019.

funcionárias, incluindo o proprietário da cantina. As cantinas não tinham características físico-funcionais de um serviço de alimentação, e sim estrutura de uma cozinha doméstica. $1^{\text {a }}$ etapa: Sensibilização

Não existem estudos que afirmem que reuniões com a Direção da escola e com proprietários das cantinas devam ser a primeira etapa do processo de implementação. Considera-se esse um momento importante de esclarecimento à comunidade escolar dos objetivos e das metas do projeto. Acredita-se que essa etapa seja essencial para o aumento da adesão ao projeto, por conceder maior segurança aos envolvidos, engajamento das partes e sucesso do resultado final.

$2^{\mathrm{a}}$ etapa: Planejamento

Na segunda etapa, as reuniões com os integrantes do projeto serviram para a padronização das ações. Foi destacado que, além de levantar quais eram os alimentos comercializados no local e as suas condições higiênico-sanitárias, avaliar a satisfação dos alunos em relação à cantina seria interessante, principalmente do ponto de vista comercial e de negócios. 
A entrega dos resultados dos dados ao proprietário do estabelecimento e à direção da escola foi feita em formato de explicação oral e com a entrega de relatório escrito. Um apontamento dos dados mais insatisfatórios e satisfatórios gerados pela pesquisa foi realizado nesse estudo. Com isto, tem-se em mãos um importante diagnóstico para a criação de estratégias a serem executadas no local (e pode ser em ordem de prioridade dos clientes). Além disso, caso os integrantes do projeto achem importante, este relatório pode ser entregue e discutido também com professores, representantes da Associação de Pais e Mestres e grupos de representação dos alunos, por exemplo.

$3^{\mathrm{a}}, 4^{\mathrm{a}}$ e $5^{\mathrm{a}}$ etapas: Diagnóstico de satisfação da cantina, análise dos resultados e justificativa para a mudança

Neste projeto, realizamos a avaliação de satisfação com alunos de ensino médio. A maioria relatou que faltavam alimentos saudáveis nas cantinas e que gostariam de mais opções e de preços menores. Bem como muitos estudantes relataram que encontraram cabelos nos alimentos. 0 questionário deve ser elaborado de acordo com a faixa etária do público e garantindo uma representatividade das turmas, turnos, alunos e professores.

A análise dos dados coletados deve ser o mais breve possível para propor um plano para mudanças, com base na opinião/satisfação dos alunos (clientes).

Amorim et al. ${ }^{9}$ e Prado et al. ${ }^{22}$ consideraram importante a realização de pesquisa de satisfação da cantina com os alunos, com intuito de se obter dados sobre suas preferências alimentares e a opinião dos alunos sobre a cantina escolar, para que, baseadas nessas informações, sejam propostas ações de educação alimentar e nutricional. Temple et al. ${ }^{23}$ avaliaram o perfil dos alimentos comercializados pelos alunos em Cape Town, África do Sul, por meio de um questionário, coletando dados sobre os alimentos trazidos por eles mesmos para a escola, os hábitos alimentares na escola, a compra de alimentos na cantina, a realização do café da manhã e o conhecimento sobre alimentação saudável, instrumento muito semelhante ao utilizado na presente pesquisa ${ }^{15,22,23}$.

$6^{\mathrm{a}}$ e $7^{\mathrm{a}}$ etapas: Diagnóstico das condições higiênico-sanitária e plano de ação

$\mathrm{Na}$ análise das condições higiênico-sanitárias, nos deparamos com algumas situações importantes. Nem todos os alimentos eram preparados no local. Muitas cantinas terceirizam os alimentos pré-prontos, o que dificultou a análise das condições higiênicas-sanitárias da etapa de preparo dos alimentos. Reforçamos a importância da realização do acompanhamento das etapas de produção e distribuição dos alimentos. Estas visitas devem ser realizadas por profissionais previamente capacitados para a padronização das coletas. Foi verificado que as cantinas escolares avaliadas apresentaram um baixo percentual de adequação em quesitos básicos relacionados ao acesso de água potável no local de produção de alimentos, estrutura física/estrutural deficitária e não condizente com as legislações sanitárias de um serviço de alimentação, ausência de um controle de pragas efetivo e periódico na área de produção e comercialização dos alimentos, falhas importantes no processo de recebimento e manipulação de alimentos, tais como ausência de controle no recebimento dos gêneros alimentícios, descongelamento dos alimentos em temperatura ambiente, higienização incorreta de frutas e verduras usadas para elaborar as preparações e armazenamento incorreto dos alimentos dentro dos equipamentos de conservação (geladeiras e freezers). Foi possível observar também falhas no processo de higienização do ambiente e de equipamentos que podem comprometer a qualidade higiênico-sanitária dos alimentos comercializados. Ainda, ambos os locais não possuíam a documentação mínima exigida, tais como: o manual de boas práticas e a descrição dos procedimentos operacionais padronizados das unidades.

Depois de aplicada a lista de verificação, os planos de ação para as respectivas cantinas foram realizados de acordo com as não conformidades encontradas. Para cada não conformidade foi proposta uma alternativa de mudança, quanto custaria, quando poderia ser realizada e quem seria responsável pela mudança/ alteração. Exemplos de ações dos planos de ação: alvará sanitário em processo de regularização; solicitação do registro de potabilidade da água no local da cantina; instalação sanitária exclusiva para a cantina; realização de uma divisão temporal do preparo dos diferentes alimentos, para que não haja contaminação cruzada; demonstração da higiene adequada de áreas como mesas e pias; arquivamento do registro do controle de pragas e vetores; colocação de etiquetas nos alimentos abertos com a validade, dentre outros.

É importante que estes planos de ação incluam custo e tempo de execução para a adequação, considerando que em alguns casos, a mudança deve ser imediata pelo fato de apresentar riscos à saúde dos clientes. No estudo de Amaral et al. ${ }^{24}$, foram entregues para o município relatórios das não conformidades encontradas nas cantinas, incluindo sugestões de melhorias, semelhante ao que foi realizado no presente estudo.

Vários autores ${ }^{21,24,25,26,27}$ utilizam listas de verificação para avaliação das condições higiênico-sanitárias das cantinas escolares. Tais listas são baseadas em diferentes legislações, como a Resolução de Diretoria Colegiada (RDC) $n^{\circ} 216$, de 15 de setembro de $2004^{28}$, a RDC ${ }^{\circ} 275$, de 21 de outubro de $2002^{29}$, a Portaria $n^{\circ} 78$, de 30 de janeiro de $2009^{30}$, e a Portaria $n^{\circ} 817$, de 10 de maio de $2013^{20}$. Destaca-se que Verdum et al. ${ }^{21}$ utilizaram a mesma lista de verificação da Portaria $n^{\circ} 817 / 2013^{20}$ utilizada nesse estudo. É importante ressaltar que não há lista de verificação específica para cantinas escolares. Este fato é importante em virtude das diferenças encontradas na realidade destes estabelecimentos, que variam de acordo com o tamanho da escola, tipo de gestão (própria ou terceirizada) e âmbito da escola (pública ou privada).

$8^{\text {a }}$ etapa: Alimentos comercializados - diagnóstico

A avaliação dos motivos pelos quais as cantinas comercializam determinados alimentos pode ser um instrumento valioso. Muitas vezes a escolha do alimento pode ser influenciada pelas 
condições estruturais do local, preferência dos alunos, influência da direção da escola, determinação de preço pela clientela ou pelo conhecimento com relação às legislações sobre as cantinas escolares.

Nesta experiência vimos que os proprietários comercializam o que os alunos mais gostam, como: pastéis fritos, refrigerantes e cachorro-quente. Na escola privada, percebe-se a venda de sanduíches e suco natural e alimentos mais elaborados como: chá-mate, minipizza, crepe e hambúrguer. Ambas consideram que os alimentos vendidos são pouco saudáveis e o proprietário da cantina da escola pública informou não saber de legislação que regulamente as cantinas escolares. Informaram que já tentaram vender alimentos saudáveis, porém não tiveram êxito e, por isso, desistiram.

0 estudo de Porto et al. ${ }^{12}$ avaliou a interferência da escola e/ou dos pais na oferta de alimentos pelas cantinas, não abordando todos os aspectos analisados na entrevista do presente estudo. Em outros estudos foram aplicados questionários aos proprietários das cantinas, não com uma entrevista, e sim com abordagem de aspectos como: qualidade nutricional dos produtos ofertados nas cantinas escolares, motivos que levavam os proprietários das cantinas a comercializarem tais alimentos, conhecimento dos proprietários das cantinas com relação à Lei do estado ${ }^{13} \mathrm{e}$ interferência da administração escolar na escolha dos alimentos ofertados na cantina $a^{9,12,17,31}$.

$\mathrm{Na}$ análise dos alimentos comercializados, é possível identificar se a cantina comercializa produtos in natura, processados e ultraprocessados. Sugere-se uma adaptação a cada região do Brasil, levando em consideração a existência de alimentos com identidade cultural e regional local. Nesse caso, o questionário foi adaptado segundo o consumo alimentar frequente das crianças e adolescentes do interior do estado do Rio Grande do Sul.

Das duas escolas avaliadas, apenas uma possuía alimentos in natura na modalidade de suco natural. Nenhuma das escolas vendia frutas. Percebeu-se a venda de alimentos elaborados no local ou de terceiros, como pastel, rissoles, sanduíches, torradas/prensados, cachorro-quente, crepe e minipizza. Os alimentos ultraprocessados identificados foram: refrigerantes, chás industrializados, pipocas de micro-ondas, achocolatados e salgadinhos. Não foi observada a venda de chicletes e balas. Quanto à publicidade, nas duas escolas, havia a presença de móveis com marcas de refrigerantes e não havia cartazes com a promoção de alimentos saudáveis no local. Sugere-se o questionamento referente à compra de alimentos da agricultura familiar e de alimentos orgânicos que poderá fomentar a abordagem desta temática no espaço escolar com o propósito de incentivar o desenvolvimento local sustentável e apoiar projetos de aquisição de alimentos da agricultura familiar e de cooperativas de pequenos produtores.

Vários autores sugeriram a realização deste diagnóstico $^{12,13,15,17,18,31,32}$. A lista sugerida e/ou utilizada pelos estudos citados engloba alimentos em geral, doces e bebidas que normalmente são vendidos nas cantinas escolares, bem como a presença dos alimentos proibidos por lei. O Manual das Cantinas Escolares Saudáveis ${ }^{15}$, Gaetani e Ribeiro ${ }^{31}$, Porto et al. ${ }^{12}$ e Willhelm et al. ${ }^{13}$ também avaliaram a presença de propagandas nos arredores da cantina que estimulem o consumo de alimentos pouco saudáveis.

\section{$9^{a}$ etapa: Implementação das ações}

As atividades de educação alimentar e nutricional (EAN) com a comunidade escolar seguiram os diagnósticos resultantes da aplicação dos questionários nas etapas prévias como: lista de verificação de boas práticas, alimentos comercializados, pesquisa de satisfação dos clientes da cantina e entrevista com o proprietário. Essas atividades tiveram o objetivo de sensibilizar a comunidade escolar para a implementação da cantina escolar saudável. As atividades foram organizadas de modo a estabelecerem o público-alvo de mudança. Quanto maior o envolvimento da comunidade escolar (alunos, professores, pais, proprietários) com a temática, supõe-se que os resultados serão melhores alcançados. Sugere-se que escolas com cantinas escolares tenham em seu planejamento anual de educação alimentar e nutricional atividades sobre a alimentação escolar neste espaço, de forma a contemplar todos os alunos e professores.

No presente estudo, com base nos diagnósticos encontrados, alguns temas foram propostos para atividades de educação alimentar e nutricional no ambiente escolar.

Para os proprietários das cantinas, os temas versaram sobre: custo e lucratividade, alimentos ultraprocessados $x$ alimentos preparados no local, utilização de etiquetas e prazo de validade nos alimentos; higienização correta das hortifrutícolas (diluições e produtos adequados); barreirais por meio de horários para evitar a contaminação cruzada; utilização e aquisição de um termômetro para verificar a temperatura em alimentos produzidos e posteriormente servidos; orientação para o método correto de descongelamento dos alimentos; capacitação sobre o manual de boas práticas e os procedimentos operacionais padronizados (POP). Estes temas foram abordados como metodologias de demonstração prática e teórica, envio de vídeos por meio de aplicativos de mensagens instantâneas e conversas.

Para os alunos, os temas escolhidos foram: diferenciação entre alimentos in natura, processados e ultraprocessados, quantidade de açúcar presente nas bebidas açucaradas, importância da realização do café da manhã e mudanças na oferta de alimentos da cantina, lanches mais saudáveis, importância do ato de cozinhar, a oxidação causada pela fritura provoca nos óleos e seus malefícios, diferenças nutricionais entre suco natural, industrializado e refrigerantes e estigma do alimento saudável entre adolescentes. No Quadro 5 está descrito o modelo de atividade realizado. Ao todo, em torno de 150 alunos foram contemplados com as ações de EAN.

Ações de educação em saúde são realizadas com intuito de promoção de alimentação saudável no ambiente escolar e utilizam atividades de educação alimentar e nutricional como uma ferramenta de intervenção nesse aspecto. Tem como intuito a melhora da qualidade do consumo alimentar dos alunos no ambiente 
Quadro 5. Atividade de educação alimentar e nutricional.

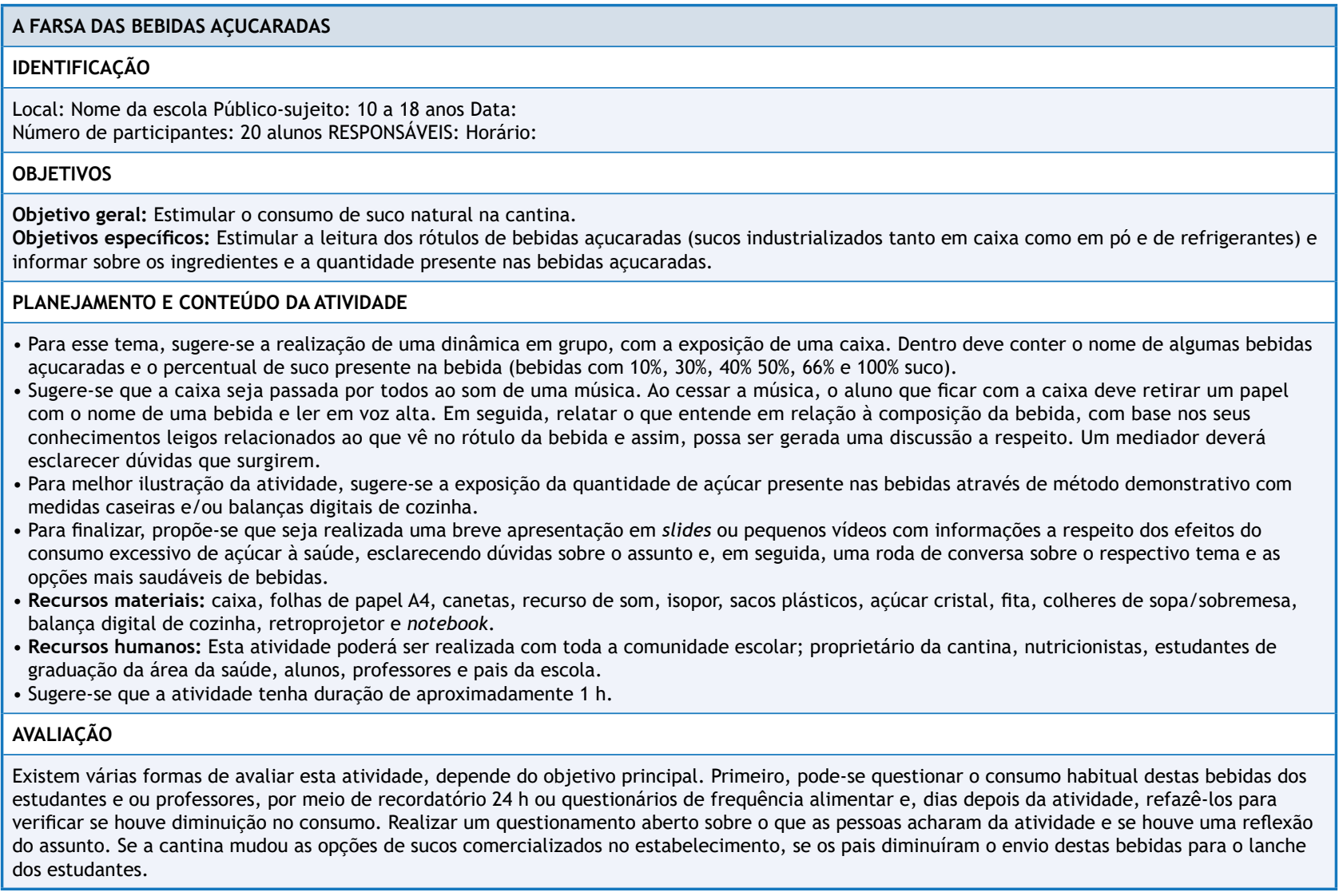

Fonte: Elaborado pelos autores, 2019.

escolar ${ }^{4,33}$. O Ministério da Saúde ${ }^{3,5,6}$ e diversas legislações estaduais estimulam a realização de ações de educação alimentar e nutricional e o incentivo ao consumo de alimentos saudáveis no ambiente escolar, associando as áreas da saúde e da educação. Para que as ações de EAN tenham efeito é importante um esforço de toda a comunidade escolar, bem como da fiscalização, para que as cantinas façam a sua parte na venda de alimentos mais saudáveis e a comunidade escolar reconheça estas mudanças como atitudes para a saúde dos escolares e professores.

Enquanto política pública, a EAN pode ocorrer em diversos setores e deverá observar os princípios organizativos e doutrinários do campo no qual está inserida. Assim, o ambiente escolar está inserido em várias esferas justificáveis para sua inserção, como a segurança alimentar e nutricional, na saúde (os princípios do Sistema Único de Saúde), na educação (os princípios da PNAE) e assim sucessivamente. A esses princípios estruturantes se somam a transição nutricional que o país vem sofrendo, o aumento acelerado de sobrepeso e a obesidade pela alteração do consumo alimentar, o que demonstra um aumento expressivo do consumo de alimentos ultraprocessados e a diminuição das práticas culinárias ${ }^{34,35}$.

\section{CONCLUSÕES}

Todas as etapas realizadas no presente estudo foram realizadas com o objetivo de iniciar a implementação da cantina saudável nas escolas. São importantes, pois demonstraram a possibilidade de estratégias para essa implementação em estabelecimentos de ensino por meio de diagnósticos e ações. Este relato de experiência é uma forma de demonstrar um caminho planejado para a comunidade escolar organizar a implementação de cantinas saudáveis, de forma lenta e gradual, em seus espaços que estejam de acordo com as legislações municipais e/ou estaduais vigentes.

Para que o processo de implementação da cantina escolar saudável assegure resultados positivos, é necessário que ocorra o apoio mútuo de toda a comunidade escolar (alunos, pais, professores, direção da escola, funcionários e proprietários das cantinas) por meio de incentivo, dedicação e colaboração dos envolvidos, através de um trabalho em conjunto, considerando a grande influência que todas as partes possuem nas escolhas $\mathrm{e}$ decisões dos alunos, incluindo também as escolhas alimentares. Deve-se ressaltar ainda que o processo de implementação da cantina escolar saudável demanda tempo e paciência de todos os envolvidos. Principalmente em se tratando das dificuldades que surgirão, é um processo que irá se desenvolver de forma lenta e gradual.

As escolas, em conjunto com a saúde e educação dos municípios, estados e das universidades, devem contribuir para o estabelecimento de Cantinas Saudáveis no ambiente escolar, prestando todo o auxílio necessário para que o processo de implementação seja realizado, regularizando as cantinas com relação às legislações existentes. 
1. Ng M, Fleming T, Robinson $M$, Thomson B, Graetz N, Margono $\mathrm{C}$ et al. Global, regional, and national prevalence of overweight and obesity in children and adults during 1980-2013: a systematic analysis for the global burden of disease study 2013. Lancet. 2014;384(9945):766-81. https://doi.org/10.1016/S0140-6736(14)60460-8

2. Conde WL, Mazzeti CMS, Silva JC, Santos IKS, Santos AMR. Estado nutricional de escolares adolescentes no Brasil: a pesquisa nacional de saúde dos escolares 2015. Rev Bras Epidemiol. 2018;21(Supl.1):1-12. https://doi.org/10.1590/1980-549720180008.supl.1

3. Ministério da Saúde (BR). Política nacional de alimentação e nutrição. Brasília: Ministério da Saúde; 2013.

4. Ministério da Saúde (BR). Resolução $N^{\circ} 26$, de 17 de junho de 2013. Dispõe sobre o atendimento da alimentação escolar aos alunos da educação básica no âmbito do programa nacional de alimentação escolar - PNAE. Diário Oficial União. 18 jun 2013.

5. Ministério da Saúde (BR). Instrutivo PSE. Brasília: Ministério da Saúde; 2011.

6. Ministério da Saúde (BR). Dez passos para a promoção da alimentação saudável nas escolas. Brasília: Ministério da Saúde; 2006[acesso 29 set 2020]. Disponível em: http://189.28.128.100/nutricao/docs/geral/ dezPassosPasEscolas.pdf

7. Agência Nacional de Vigilância Sanitária - Anvisa. Resolução $\mathrm{RDC} \mathrm{N}^{\circ} 24$, de 29 de junho de 2010. Dispõe sobre a oferta, propaganda, publicidade, informação e outras práticas correlatas cujo objetivo seja a divulgação e a promoção comercial de alimentos considerados com quantidades elevadas de açúcar, de gordura saturada, de gordura trans, de sódio, e de bebidas com baixo teor nutricional. Diário Oficial União. 30 jun 2010.

8. Ministério da Saúde (BR). Portaria interministerial $\mathrm{N}^{\circ}$ 1.010, de 8 de maio de 2006. Institui as diretrizes para a promoção da alimentação saudável nas escolas de educação infantil, fundamental e nível médio das redes públicas e privadas, em âmbito nacional. Diário Oficial União. 9 maio 2006.

9. Amorim NFA, Schmit BAS, Rodrigues MLCF,

Recine EGI, Gabriel CG. Implantação da cantina escolar saudável em escolas do Distrito Federal, Brasil. Rev Nutr. 2012;25(2):203-17. https: / / doi.org/10.1590/S1415-52732012000200003

10. Governo do Estado de São Paulo. Normas para funcionamento de cantinas escolares. São Paulo: Governo do Estado de São Paulo; 2005[acesso 28 jun 2017]. Disponível em: http://www.educacao.sp.gov.br/a2sitebox/ arquivos/documentos/953.pdf

11. Wognski ACP, Ponchek VL, Dibas EES, Orso MR, Vieira LP, Ferreira BGCS et al. Comercialização de alimentos em cantinas no âmbito escolar. Braz J Food Technol. 2019;22:1-12. https://doi.org/10.1590/1981-6723.19818

12. Porto EBS, Schmitz BAS, Recine E, Rodrigues MLCF. School canteens in the Federal District, Brazil and the promotion of healthy eating. Rev Nutr. 2015;28(1):29-41. https://doi.org/10.1590/1415-52732015000100003

13. Willhelm FF, Ruiz E, Oliveira AB. Cantina escolar: qualidade nutricional e adequação à legislação vigente. Rev HCPA. 2010;30(3):266-70.

14. Ministério da Saúde (BR). Regulamentação da comercialização de alimentos em escolas no Brasil: experiências estaduais e municipais. Brasília: Ministério da Saúde; 2007.

15. Ministério da Saúde (BR). Manual das cantinas escolares saudáveis: promovendo a alimentação saudável. Brasília: Ministério da Saúde; 2010.

16. Schmitz BAS, Recine E, Cardoso GT, Silva JRM, Amorim NFA, Bernardon R et al. A escola promovendo hábitos alimentares saudáveis: uma proposta metodológica de capacitação para educadores e donos de cantina escolar. Cad Saude Publica. 2008;24(Supl.2):s312-22. https://doi.org/10.1590/S0102-311X2008001400016

17. Gabriel CG, Vasconcelos FAG, Andrade DF, Schmitz BAS. First law regulating school canteens in Brazil: evaluation after seven years of implementation. Arch Latinoam Nutr. 2009;59(2):128-38.

18. Gabriel CG, Santos MV, Vasconcelos FAG, Milanez GHG, Hulse SB. Cantinas escolares de Florianópolis: existência e produtos comercializados após a instituição da lei de regulamentação. Rev Nutr. 2010;23(2):191-9. https://doi.org/10.1590/S1415-52732010000200002

19. Agência Nacional de Vigilância Sanitária - Anvisa. Categorização dos serviços de alimentação: elaboração e avalição da lista de avaliação. Brasília: Agência Nacional de Vigilância Sanitária; 2013.

20. Ministério da Saúde (BR). Portaria № 817 , de 10 de maio de 2013. Aprova as diretrizes nacionais para a elaboração e execução do projeto-piloto de categorização dos serviços de alimentação para a Copa do Mundo FIFA 2014. Diário Oficial União. 13 maio 2013.

21. Verdum DP, Silva JP, Copatti F. Condições higiênico-sanitárias das cantinas escolares da rede estadual de ensino no município de Palmeira das Missões, Rio Grande do Sul. Vigil Sanit Debate. 2017;5(4):17-23. https://doi.org/10.22239/2317-269x.00960

22. Prado BG, Guimarães LV, Lopes MA, Bergamaschi DP. Efeito de ações educativas no consumo de alimentos no ambiente escolar. Nutrire Rev Soc Bras Aliment Nutr. 2012;37(3):281-92. https://doi.org/10.4322/nutrire.2012.022

23. Temple NJ, Steyn NP, Myburgh NG, Nel JH. Food items consumed by students attending schools in different socioeconomic areas in Cape Town, South Africa. Nutrition. 2006;22(3):252-8. https://doi.org/10.1016/j.nut.2005.07.013

24. Amaral DA, Souza CF, Barcellos LS, Tonini PM, Ferreira MA, Ferreira CC. Avaliação das condições higiênico-sanitárias das cantinas de escolas públicas de um município do interior de São Paulo. Hu Rev. 2012;38(1/2):111-7. 
25. Gomes RNS, Lima MIS, Gomes FO, Gomes VTS, Gomes MS, Lago EC. Qualidade higiênico-sanitária de alimentos produzidos em cantinas de escolas públicas de Codó/MA. Rev Interd. 2015;8(1):37-46.

26. Porto EBS, Schmitz BAS, Recine E, Rodrigues MLCF. Condições higiênico-sanitárias das cantinas de escolas públicas e privadas do Distrito Federal, Brasil e seus fatores associados. Vigil Sanit Debate. 2015;3(4):128-35. https://doi.org/10.3395/2317-269x.00317

27. Silva LM, Silveira JT, Barboza PP, Moreira AS, Moura FA, Brasil CCB. Avaliação das condições higiênicas das escolas municipais de ensino fundamental de Itaqui, RS. An Salao Intern Ensino Pesq Ext. 2015;7(2):1-2.

28. Agência Nacional de Vigilância Sanitária - Anvisa. Resolução RDC No 216, de 15 de setembro de 2004. Dispõe sobre regulamento técnico de boas práticas e serviços de alimentação. Diário Oficial União. 16 set 2004.

29. Agência Nacional de Vigilância Sanitária - Anvisa. Resolução RDC № 275, de 21 de outubro de 2002. Dispõe sobre o regulamento técnico de procedimentos operacionais padronizados aplicados aos estabelecimentos produtores/industrializadores de alimentos e a lista de verificação das boas práticas de fabricação em estabelecimentos produtores/industrializadores de alimentos. Diário Oficial União. 6 nov 2002.
30. Governo do Estado do Rio Grande do Sul. Portaria № 78, de 30 de janeiro de 2009. Aprova a lista de verificação em boas práticas para serviços de alimentação, aprova normas para cursos de capacitação em boas práticas para serviços de alimentação e dá outras providências. Diário Oficial do Estado. 28 jan 2009.

31. Gaetani RS, Ribeiro LC. Products sold in school canteens of the municipality of Ribeirão Preto. Rev Bras Promoc Saude. 2015;28(4):587-95. https://doi.org/10.5020/18061230.2015.p587

32. Giacomelli SC, Londero AM, Benedetti FJ, Saccol ALF. Comércio informal e formal de alimentos no âmbito escolar de um município da região central do Rio Grande do Sul. Braz J Food Technol. 2017;20:1-9. https://doi.org/10.1590/1981-6723.13616

33. Ramos FP, Santos LAS, Reis ABC. Educação alimentar e nutricional em escolares: uma revisão de literatura. Cad Saude Publica. 2013;29(11):2147-61. https://doi.org/10.1590/0102-311×00170112

34. Ministério da Saúde (BR). Guia alimentar para a população brasileira. 2a ed. Brasília: Ministério da Saúde; 2014.

35. Ministério da Saúde (BR). Marco de referência de educação alimentar e nutricional para as políticas públicas. Brasília: Ministério da Saúde; 2012.

\section{Agradecimentos}

Fundo de Incentivo à Extensão (FIEX) da Universidade Federal de Santa Maria.

\section{Contribuição dos Autores}

Braz NG, Brasil CCB, Bohrer CT, Paini D, Kirsten VR - Concepção, planejamento (desenho do estudo), aquisição, análise, interpretação dos dados e redação do trabalho. Leal GVS - Concepção, planejamento (desenho do estudo) e redação trabalho. Todos os autores aprovaram a versão final do trabalho.

Conflito de Interesse

Os autores informam não haver qualquer potencial conflito de interesse com pares e instituições, políticos ou financeiros deste estudo.

Licença CC BY-NC atribuição não comercial. Com essa licença é permitido acessar, baixar (download), copiar, imprimir, compartilhar, reutilizar e distribuir os artigos, desde que para uso não comercial e com a citação da fonte, conferindo os devidos créditos de autoria e menção à Visa em Debate. Nesses casos, nenhuma permissão é necessária por parte dos autores ou dos editores. 